\title{
Erratum to: Implementing Meritocracy in Senior Public Administration: the Dilemma for Chilean Politicians
}

\author{
Mauricio Olavarría-Gambi ${ }^{1}$ - Andrés Dockendorff ${ }^{1}$
}

Published online: 9 September 2016

(C) Springer Science+Business Media New York 2016

\section{Erratum to: Public Organiz Rev \\ DOI 10.1007/s11115-016-0360-4}

The original version of this article unfortunately contained a mistake. The author biographies were missing:

Mauricio Olavarría-Gambi is Professor at the Government Studies Program of the University of Santiago, Chile and holds a Ph.D. in Policy Studies from the University of Maryland at College Park.

Andrés Dockendorff is Associate Researcher at the Government Studies Program of the University of Santiago, Chile and a Ph.D. Student at the Department of Government, University of Essex, England.

The online version of the original article can be found at http://dx.doi.org/10.1007/s11115-016-0360-4.

Mauricio Olavarría-Gambi mauricio.olavarria@usach.cl

1 Avda. Bernardo O'Higgins 3363, Estación Central, Santiago, Chile 